\title{
Influence of Psychological Factors in Food Risk Assessment - A Review
}

Sarah C. Jenkins ${ }^{a}$, Adam J. L. Harris ${ }^{a}$ and Magda Osman ${ }^{b}$

${ }^{a}$ Department of Experimental Psychology, University College London, 26 Bedford Way, London, WC1H OAP.

${ }^{b}$ Biological and Experimental Psychology Group, School of Biological and Chemical Sciences, Queen Mary University of London, Mile End Road, London, E1 4NS.

Correspondence concerning this article should be addressed to Sarah C. Jenkins, Department of Experimental Psychology, University College London, 26 Bedford Way, London, WC1H OAP, UK.

E-mail: sarah.jenkins@ucl.ac.uk

Word count (main text): 9039 (excluding abstract, tables and figure captions) 


\begin{abstract}
Background: Typically, food-related risk assessments are carried out within a four step, technical framework, as detailed by the Codex Alimentarius Commission (World Health Organization/ Food and Agricultural Organization of the United Nations, 2015). However, the technical framework presumes a level of 'objective risk' and does not take into account that risk is complex and psychologically constructed, something which is rarely acknowledged within risk analysis as a whole. It is well documented that people's perceptions of risk are based on more than merely probability of occurrence, but reflect other non-technical psychological factors (e.g., risk origin, severity, controllability, familiarity). Moreover, the basis of these risk perceptions is largely similar for experts and non-experts.
\end{abstract}

Scope and Approach: In this review, we consider each stage of the risk assessment process from a psychological perspective, reviewing research on non-technical factors which could affect assessments of risk and subsequent risk management decisions, with a particular focus on food safety.

Key Findings and Conclusions: We identify 12 factors from the psychological literature which could potentially influence how risks are assessed and characterised. Drawing on insights from this research, we propose a number of recommendations to standardise approaches in risk assessment. Acknowledging and working with the subjectivity of risk is key to ensuring the efficacy of the wider risk analysis process.

Keywords: food safety; food technologies; risk assessment; risk perception; risk analysis

\title{
Disclaimer Notice
}

This report is independent research funded by the Food Standards Agency (FSA) for the project 'Measures of a World Class Regulator'. The views expressed in this publication are those of the authors and not necessarily those of the FSA. 


\section{Contextualising the Issues}

Food consumption risks are a unique type of risk, in that consumers face them daily (Fischer $\&$ De Vries, 2008). Despite this, eating is not typically perceived as hazardous, except during food safety scares $^{1}$. In order to manage food risks, a risk analysis approach is used, consisting of three distinct, but related components: risk assessment, risk management and risk communication, as defined by the Codex Alimentarius Commission (CAC) (World Health Organization [WHO]/Food and Agricultural Organization of the United Nations [FAO], 2015). This approach has been adopted globally. Risk assessment is the first stage of risk analysis and provides the scientific foundation for the process (WHO/FAO, 2006). It has a highly influential role in risk analysis, given the following stages depend on it. Risk assessment has been defined as "the science of understanding hazards, the likelihood of occurrence and consequences if they do occur" (European Commission Scientific Committee for Food, 1997, Section 6, para. 6). Risk management is distinct from risk assessment, and refers to the process of "weighing policy alternatives...considering risk assessment and other factors relevant for the health protection of consumers... and, if needed, selecting appropriate prevention and control options" (WHO/FAO, 2015, p.120). Risk communication has been defined as "the interactive exchange of information and opinions throughout the risk analysis process concerning risk, risk-related factors and risk perceptions, among risk assessors, risk managers, consumers, industry, the academic community and other interested parties, including the explanation of risk assessment findings and the basis of risk management decisions" (WHO/FAO, 2015, p.120).

Whilst risk assessment is defined as the first stage of risk analysis, in reality there is usually an interactive, iterative relationship between the three stages, particularly between risk assessment and risk management (WHO/FAO, 2006, 2009). As such, risk perceptions are inextricably linked to the whole risk analysis process. Risk managers are responsible for deciding whether a risk assessment is required (WHO/FAO, 2006); their judgement (initial risk perception) will be influenced by a variety of personal, social, cultural and organisational values (McDaniels, 1998). Whilst the subjective nature of risk has been recognised in relation to risk management and communication efforts, there still exists the tendency to assume that risk assessments measure and reflect 'objective risk' (Slovic, 1999, 2001). Yet this assumption fails to take into account that the risk assessment process requires many subjective judgements and choices to be made (WHO/FAO, 2006), leaving assessments potentially susceptible to the influence of psychological factors, hitherto a relatively unexplored notion. This

\footnotetext{
${ }^{1}$ Notable food safety scares in the UK include the horsemeat scandal in 2013 and the BSE crisis in the late 80s and 90s. Similar food scares in other countries include the 2008 Chinese baby milk scandal, and the 1993 US 'Jack in the Box' e-coli scandal.
} 
review therefore focusses on the risk assessment stage, though much of the research highlighted is also relevant to the risk management and communication stages.

The continued advancement of food technologies and production processes brings the potential advent of new risks, which must be assessed and managed. Given that preparing for future risk assessment challenges forms one of EFSA's strategic objectives (European Food Safety Authority, 2020), a reflection on the factors which could affect risk assessments (and the wider efficacy of risk management/communication efforts) is therefore particularly timely. Moreover, it is of relevance to all food safety regulators who adopt the basic procedures set out by the CAC. Such reflection is key to ensuring that risk analysis processes are agile enough to assess and manage new risks that might arise as food technology evolves.

The numerous interpretations and uses of the terms 'risk' and 'hazard', both across cultures and groups (e.g., practitioners, policy makers, businesses, public) (Scheer et al., 2014) pose a significant challenge for risk analysis. For instance, public authorities define risk as the 'product of the probable occurrence and scale of damage' and hazard as related to the 'inherent properties in a substance' (Scheer et al., 2014). Experts from business and environmental/consumer organisations, however, define risk as 'possible danger' and hazards as 'actual danger', if they make a distinction between the terms at all (Scheer et al., 2014). Different definitions of the same term may lead to different risk acceptance thresholds, and thus different risk management strategies (Scheer et al., 2014). In this review, we follow the definitions provided by the CAC (WHO/FAO, 2015) - an established authority that the majority of food safety regulators refer to. The CAC defines hazard as "a biological, chemical or physical agent in, or condition of, food with the potential to cause an adverse health effect" (WHO/FAO, 2015). Importantly, the potential for adverse effects may never occur, for instance if one is not exposed to the hazard. In contrast, risk takes into account the probability that this adverse effect will occur, and is defined as "a function of the probability of an adverse health effect and the severity of that effect, consequential to a hazard(s) in food" (WHO/FAO, 2015). In the following, we consider the consequences of the highlighted factors for risk.

\section{Subjective Risk}

Technical risk assessments focus on specific, measurable concepts such as 'no observable effect levels' (NOEL) and 'maximum residue limits' (MRLs) and consider their probability of occurrence. Such assessments assume that there is 'objective risk', whereby the probability and consequences of adverse events are produced by physical/natural processes which can be objectively quantified (Slovic, $1999,2001)$. This can be said to reflect a 'realist' view of risk, which assumes the resulting assessment is a true representation of the hazard, and thus should be used as a guiding principle for risk management (Klinke \& Renn, 2002). However, such a view fails to account for the subjective nature 
of risk, and indeed risk assessment (Slovic, 2001), which implies that it is unrealistic for risk experts to assume that risk is always (or even ever) objective. Moreover, whilst risk estimates are often based on theoretical models, there is still a subjective component to them. Slovic (2001) highlights the subjective judgements experts make at every stage of risk assessment, for instance when structuring the risk problem, deciding which consequences to include in analyses, identifying and estimating exposures, and choosing the dose-response relationship. Even when experts present objective information such as mortality risk, subjective judgements guide choice of how to express this (in terms of deaths per million, deaths per unit of concentration, loss of life expectancy etc.), choices which may influence risk management decisions.

Issues pertaining to the subjective nature of risk have been made transparent by seminal work using the psychometric paradigm developed by Fischhoff, Slovic, Lichtenstein, Read and Combs (1978). The psychometric paradigm involves asking individuals not only how they perceive a risk, but also to characterise the 'personality of hazards' by rating hazards on a series of qualities such as severity, familiarity and level of knowledge, which are believed to influence perception and acceptance of risk (Slovic, 2010). The paradigm has highlighted the multi-dimensional nature of risk perceptions and has consistently highlighted a number of (non-technical) psychological factors which affect how a risk is perceived and its acceptability (e.g., Fischhoff et al., 1978; Fox-Glassman \& Weber, 2016; Slovic, 1987, 2010; Starr, 1969).

\section{Expert and lay risk perceptions.}

It has often been assumed that experts perceive risks in a different way than the public do, with perceptions of the former more closely related to technical/statistical estimates and thus more veridical than the public's risk perceptions (Rowe \& Wright, 2001; Wright, Bolger, \& Rowe, 2002, 2009). However, despite its prevalence in the literature and intuitive appeal the evidence for this assumption is scant (Rowe \& Wright, 2001; Sjöberg, 2002). We are unaware of research specifically focussing on food risk assessors (an important direction for future research). However, research with experts more generally (e.g., Biology professors) indicates that although there may be differences in levels of perceived risk between experts and the public (e.g., Savadori et al., 2004), the general basis of perceived risk is similar across the two groups, in reflecting qualitative characteristics (i.e., dread, newness, (Sjöberg, 2002; see Rowe \& Wright, 2001 for a review comparing risk judgements of experts and non-experts). The differing levels of perceived risk may therefore simply result from a different weighting of characteristics across the two groups. Indeed, when expert and the public ranked food safety hazards, their rationales behind the ranks were similar, with differences suggested to result from the differential assignment of priorities (Webster et al., 2010). Moreover, Wright et al. (2002) found that judgements of expert insurance underwriters were susceptible to the same systematic 
biases as those of non-experts. Essentially, there is no evidence that the basis of experts' risk perceptions is radically different from those of non-experts (Sjöberg, 2002).

The risk assessment process is based on a number of idealistic assumptions about the nature of risk, when in fact risk is far more complex and subjective, something that is rarely acknowledged. Indeed, technical risk assessments ignore the psychological processing of risk (Klinke \& Renn, 2002), yet the research outlined above indicates that psychological factors could influence both expert risk assessment and management. An awareness of these factors is crucial to mitigate against their influence. In addition, such awareness could increase the efficacy of the wider risk analysis process and be used to inform the development of effective risk management and communication strategies (Frewer et al., 2016; Klinke \& Renn, 2002).

In the following, we consider each stage of the risk assessment process from a psychological perspective, reviewing research on non-technical factors which could affect risk assessments and thus subsequent risk management/communication efforts, with a particular focus on food. The relative lack of research examining expert risk perceptions means we predominantly focus on studies with non-expert respondents. We acknowledge that risk assessors, will, by nature, be more expert in their fields and thus more familiar with the hazard they are assessing than non-experts, though emphasise that this will not necessarily be the case for risk managers or risk communicators. As outlined above, however, the best available evidence suggests that the same psychological factors that influence nonexperts' risk judgements will also influence those of expert risk assessors (Rowe \& Wright, 2001; Sjöberg, 2002; Wright et al., 2009). Nevertheless, in the interests of transparency, throughout the review we explicitly highlight the group investigated in specific empirical studies. ${ }^{2}$ Whilst situated within the risk assessment stage, our literature review yields a number of practical recommendations of relevance across risk analysis, highlighted throughout the article.

\section{Risk Assessment}

In order to standardise risk assessment processes, the CAC (2015) identified four stages of risk assessment:

- Hazard identification - identification of biological, chemical and physical agents capable of causing adverse health effects.

- Hazard characterisation - qualitative or quantitative evaluation of the nature of the adverse health effects. A dose-response assessment should be performed for chemical agents, and for biological/physical agents if data is obtainable. A dose-response assessment is a

\footnotetext{
${ }^{2}$ When referring to non-expert groups, we use the terms laypeople and the public interchangeably.
} 
determination of the relationship between the magnitude of exposure to the agent, and the severity and/or frequency of adverse health effects.

- Exposure assessment - qualitative or quantitative evaluation of the likely intake of biological, chemical and physical agents via food, or other exposure.

- Risk characterisation - the qualitative and/or quantitative estimation of the probability of occurrence and severity of potential adverse health effects in a given population, based on the above three components.

Following the identification of a hazard, the steps of assessment are not necessarily fixed (WHO/FAO, 2006). The ultimate goal of risk assessment is the production of a qualitative and/or quantitative risk estimate, based on available information. The uncertainties inherent at every stage mean that often judgements are not based on evidence (as it is unavailable) (Hart et al., 2019). As a result, the process, and subsequent risk management/communication efforts, are vulnerable to the influence of psychological factors, as detailed below and summarised in Table 1.

\section{Hazard Identification}

Initial hazard identification identifies effects that are considered adverse, regardless of whether a specific mechanism, or certain dose, is required to produce the effect (these factors are considered in subsequent risk assessment stages).

\section{Origin.}

Hazards can be broadly divided into two main categories according to their origin - natural or technological. The public typically perceive high risks for man-made, technological hazards, such as chemicals (Slovic, 1987) and nuclear power (Fischhoff et al., 1978). Risks arising from such hazards are deemed less acceptable by the public (Fischhoff et al., 1978).

Similarly, in a food safety context, the public distinguishes technological from natural food hazards (Siegrist, 2003). Higher public risk perceptions are consistently found for technological hazards, such as those relating to food processing and production (e.g., hormones, pesticides, antibiotics and genetic modification [GM]), than for more natural, lifestyle hazards (e.g., food poisoning, diet) (Kaptan et al., 2017; Miles et al., 2004). The latter are also perceived as more under personal control (Frewer et al., 1994). Relatedly, the public believe that the responsibility for good risk management depends on the hazard's origin, with more regulatory and governmental responsibility assumed for technological hazards (van Kleef et al., 2006).

The public's higher risk perceptions of man-made, technological food hazards likely result from a preference for naturalness and, indeed, natural foods (Rozin et al., 2012). Although, scientifically speaking, naturalness does not necessarily equate to less risk, or a product being healthier or tastier, this is not always recognised by the public (Rozin, 2006), with perceptions of 
'tampering with nature' predicting risk perceptions (Sjöberg, 2000). The more important naturalness is to a consumer, the more negatively they evaluate new food technologies (Román et al., 2017). Indeed, consumers perceive the same risk as less acceptable when it relates to technologically cultured meat (from stem cells) versus traditionally produced meat (Siegrist \& Sütterlin, 2017).

Problematically, food technologies have risk characteristics which are often associated with high levels of public concern: the risk is involuntary, in that the consumer is not always aware of the technology applied to foods (nor can they observe it), and uncontrollable, in that once the technology has been applied, it is typically irreversible (Cardello, 2003). If consumers believe the risk is involuntary and uncontrollable, in addition to perceiving technology-related food hazards as unnatural or artificial, it can lead to an increase in perceived risk (Siegrist et al., 2008).

Compounding the problem further for risk managers is the fact that many innovations in food are technological, and consequently continually advancing (e.g., food irradiation and nanotechnology). The newer the technology, inevitably the less is known about the toxicological nature of the hazard, the likelihood of exposure, and the risk to the public. Consequently, risk assessors may adopt an excessively conservative, precautionary approach to such hazards. Such an approach relates to the concept of the 'precautionary principle', which, although lacking a standardised definition (Scheer et al., 2014), generally refers to a 'better safe than sorry' approach, whereby protective action is taken before there is conclusive proof of harm.

\section{Implications.}

The aforementioned research indicates distinctions are made between hazards which are natural and those which are man-made, which has downstream effects on perceived risk, acceptance and concern levels.

\section{Hazard Characterisation}

Hazard characterisation categorises the nature of the effects of the hazards. Whilst typically effects are characterised as adverse or not, such a classification may be vulnerable to bias. Similarly, hazardous effects might nevertheless be more or less likely to be classified as adverse, as a result of characteristics objectively unrelated to such a classification. Two components are consistently shown to account for a large proportion of variance in public risk perception: dread and knowledge (Fischhoff et al., 1978; Fox-Glassman \& Weber, 2016). These components are also observed in relation to the public's perceptions of food hazards (e.g., Cunha et al., 2010; Fife-Schaw \& Rowe, 1996, 2000; Kirk et al., 2002; Siegrist et al., 2006).

\section{Dread.}

Dread is highly consequential for judgements of risk. It relates to catastrophic potential, fatal consequences, unequal distribution of risks and benefits, and lack of perceived control (Slovic, 1987). 
Hazards scoring highly on dread (e.g., chemical fertilisers, herbicides and pesticides) are associated with increased public risk perceptions (Fischhoff et al., 1978; Slovic, 1987). They are also associated with a greater public desire for regulations to reduce risk levels (Slovic \& Weber, 2002). High dread levels in combination with unknown risk qualities may lead to stigmatisation of a product or technology (Finucane, Slovic, et al., 2000), whereby public risk perceptions are dominated by a negative feature(s) (Slovic et al., 1991). Public reactions to beef during the Bovine Spongiform Encephalopathy (BSE) crisis are a notable example of how readily food items can be stigmatised.

Within a food safety context, dread has been shown to relate to factors including: worry, concern, likelihood of harm, voluntariness, seriousness of harm, seriousness for future generations or vulnerable groups, potential for disastrous consequences and delayed effects (Fife-Schaw \& Rowe, 1996; Kirk et al., 2002; Savadori et al., 2004; Siegrist et al., 2006; Sparks \& Shepherd, 1994). In studies featuring lay participants, food hazards scoring highly on these factors include: microbiological contamination (e.g., botulism, produce containing pesticide/hormone residue, GM, irradiation technology and BSE (Cunha et al., 2010; Fife-Schaw \& Rowe, 1996; Keller et al., 2006; Kirk et al., 2002; Siegrist et al., 2006; Sparks \& Shepherd, 1994). Notably, the way the hazard is described also influences the public's dread ratings, with specific examples of microbiological contaminants (e.g., salmonella) receiving higher ratings than a generic example (e.g., bacterial contamination) (Sparks \& Shepherd, 1994).

\section{Knowledge.}

At the 'unknown' end of the knowledge dimension are hazards that are poorly understood (by the public and/or the risk assessor), which may be new, unknown to those exposed, and yield delayed effects, such as chemical technologies (Slovic, 1987). The extent to which a hazard's impacts are believed to be unknown has been linked to increased public risk perceptions (Sjöberg, 2001), and higher levels of stigmatisation (Finucane, Slovic, et al., 2000). Familiarity can also be said to relate to knowledge (Fischhoff et al., 1978), in that low familiarity is typically associated with low levels of knowledge. Moreover, lower levels of familiarity are linked to increased risk perceptions (Slovic, 1987).

Within the food domain, knowledge has been identified as a key component of the public's perception of risks (Kirk et al., 2002; Sparks \& Shepherd, 1994). These studies have highlighted factors such as perceived level of scientific knowledge, accuracy of the layperson's assessment of the risk, the extent to which the public know if the food contains the risk, and level of control over the risk, as underpinning the knowledge component. GM technology, irradiated foods and pesticide residue are perceived as unfamiliar (Ohtsubo \& Yamada, 2007) and 'unknown' (Sparks \& Shepherd, 1994), leading to increased risk perceptions and concern about their potential (unknown) side effects (Miles \& Frewer, 2001; Savadori et al., 2004). Conversely, dietary and nutritional hazards, as well as 
microbiological hazards, consistently score high on the knowledge dimension (Fife-Schaw \& Rowe, 1996; Siegrist et al., 2006; Sparks \& Shepherd, 1994).

Risks, benefits and the affect heuristic.

The affect heuristic proposes that positive and negative affect influence people's judgements and decisions (Finucane, Alhakami, et al., 2000; Slovic et al., 2002, 2004, 2007). Notably, Slovic and Peters (2006) suggested that people rely on the affect evoked by a hazard when assessing its associated risks and benefits: negative affect is associated with increased risk perceptions (Keller et al., 2006; Siegrist et al., 2008) and decreased benefit perceptions (Siegrist et al., 2016).

Although risk and benefits are separate entities, they are typically positively correlated in reality. Whilst activities high in benefit can be high or low in risk, those that are low in benefit are unlikely to be high in risk, as, on this basis, they would be prohibited (Finucane, Alhakami, et al., 2000). Despite this, people perceive the two as negatively correlated. Activities which are high in benefit are perceived as low in risk and vice versa (Alhakami \& Slovic, 1994), a pattern observed in both experts and laypeople (Savadori et al., 2004; Slovic et al., 1999). Furthermore, this inverse relationship has been found to be influenced by a person's general affective evaluation of the activity, with more favourable evaluations associated with weaker negative correlations (Alhakami \& Slovic, 1994). When additional information is provided to increase either perceived benefit or risk, it leads to decreased ratings of the non-manipulated factor (Alhakami \& Slovic, 1994; Finucane, Alhakami, et al., 2000). For instance, providing information about benefits can reduce perceptions of risk (Frewer et al., 1998; Siegrist et al., 2000).

The inverse relationship between risks and benefits has been shown for herbicides, pesticides GM of both plants and animals and irradiation (Finucane, Alhakami, et al., 2000; Frewer et al., 1998; Savadori et al., 2004). Problematically, as more innovative food technologies are developed, there is not always an even distribution of perceived risks and benefits for consumers. For instance, with genetically modified foods, the perceived benefits are more towards farmers and food manufacturers, rather than consumers. This presents a challenge as public acceptance of innovative food technology is influenced by perceptions of its potential costs and benefits, to both individual consumers, and to society (Ronteltap et al., 2007). When food technologies have benefits for the consumer (e.g., artificial sweeteners, convenience food), they are perceived as less dreadful than those with less obvious benefits (e.g., genetically modified foods, food irradiation) (Siegrist et al., 2006). However, if a risk is perceived as extremely severe, a perceived benefit may not be enough to outweigh it, such that the risk will not be accepted.

\section{Implications and recommendations.}

Dread is a key influence on how the public perceive risks and is closely related to other characteristics, such as knowledge - high levels of dread are associated with low levels of knowledge, which both 
affect worry, concern and acceptability perceptions. By the very nature of their work, risk assessors will typically be both knowledgeable and familiar with the hazard and might therefore have a higher threshold for concern than the public (and possibly risk managers). Level of knowledge and familiarity could also influence the management strategy adopted. If a hazard is perceived as unknown, then risk managers could provide the public with more information. Alternatively, if the hazard is so dreaded that even risk communication would not reduce it, a risk manager might delay approval of a substance in order to avoid losing public confidence.

Public perceptions of benefits are often inversely related to risk perceptions. Whilst regulators currently focus solely on the assessment of potential risk, benefit assessment might be profitably included in governance processes, so the risk/benefit trade-off can be evaluated (Frewer, 2017). Such an inclusion is anticipated to reduce public concern and outright rejection of emerging food technologies. More generally, risk managers should include information about benefits alongside information about risks in risk communications, particularly if the focal hazard is associated with high levels of dread.

\section{Exposure Assessment}

Exposure assessment involves assessing who will be exposed to the risk, how many, to what extent, and how this exposure will take place.

\section{Population identity.}

Once risk assessors have identified the population exposed to the risk (or sub-populations, such as vulnerable groups - children, older adults) and estimated their exposure to the risk, risk managers must make decisions based on this estimate. The specific risk management decisions taken (or at least the public's acceptance of them) might vary, as certain groups have been shown to evoke differential amounts of worry and concern. For instance, hazards which affect children evoke more public worry and concern, with threat to future generations identified as a key contributor to dread risk (Slovic, 1987). The public believe GM and irradiation will affect future generations (Ohtsubo \& Yamada, 2007), and thus the technologies are associated with health concerns (Miles \& Frewer, 2001). Pesticide use was associated with increased public concern for vulnerable groups (e.g., children and elderly people) (Miles \& Frewer, 2001).

\section{Proportion of population exposed.}

Starr (1969) proposed that the acceptability of a risk is inversely related to the number of people exposed to the risk. In combination with dread and unknown risk, this factor emerged from subsequent studies using the psychometric paradigm (e.g. Slovic, 1987), and replicated in the food domain (Sparks \& Shepherd, 1994). However, other similar studies which have included the characteristic 'number of people exposed' found this characteristic was more strongly related to the 
overall 'dread' factor (Fife-Schaw \& Rowe, 1996; Fischhoff et al., 1978). Food hazards perceived by the public to affect large numbers of people include environmental contamination, BSE, pesticide residues, salmonella, listeria and botulism (Fife-Schaw \& Rowe, 1996; Sparks \& Shepherd, 1994).

Contrastingly, other research suggests that the relationship between risk perceptions and the number of people exposed is not clear cut. Our sensitivity to a physical stimulus diminishes as its magnitude increases (Fechner, 1966). For instance, where number of lives is concerned, whilst we are sensitive to the difference between 0 and 1 deaths, we are less sensitive to bigger changes (e.g., the difference between 420 deaths and 520 deaths), a concept termed 'psychophysical numbing' (Fetherstonhaugh et al., 1997).

Additionally, the way the number of people exposed is represented in the risk assessment could also have implications for risk management. Individuals are more sensitive to proportions of people at risk than the absolute number of people at risk (Fetherstonhaugh et al., 1997). Risk perceptions are also higher when, for example, number of deaths is presented as 'kills 1,286 out of 10,000 people' versus 'kills 24.14 out of 100' (Yamagishi, 1997). Similar results have been observed with experts - when a patient's risk of violence was expressed as a frequency (e.g., '10 out of 100'), risk perceptions were higher than when risk was expressed as a percentage (e.g., '10\%') (Slovic et al., 2000). The type of frequency format used has also been shown to affect laypeople's risk perceptions and decision-making, with those who saw a ' 1 in X' format more likely to overestimate a risk and take a precautionary safety measure compared to those who saw a ' $N$ in $X^{*} N$ ' format (Sirota et al., 2018).

Time frame.

Typically, more is known about the acute effects of a hazard, rather than more chronic, longer-term impacts, which may be less well-specified. As previously highlighted, the 'unknown' dimension is consistently associated with increased risk perceptions (Fischhoff et al., 1978; Fox-Glassman \& Weber, 2016; Slovic, 1987; Slovic et al., 1982). Time wise, increased public concern is seen for the long-term effects of pesticide use and GM (Miles \& Frewer, 2001).

For exposure assessments, EFSA makes a distinction between two time frames: acute and chronic (European Food Safety Authority, 2019). Acute exposure is typically one off, or short term, and refers to a period up to 24 hours. Chronic exposure is longer term, covering anything from daily exposure over months or years, up to an entire lifetime. Whilst EFSA prescribes that the time period that the assessment refers to should be made clear (Hart et al., 2019), and expressed quantitatively wherever possible (EFSA Scientific Committee, 2012), it does not suggest a specific way this should be expressed. The scale used to express time frame does, however, have a clear influence on risk perceptions. Framing a risk message so that the risk seems more immediate (days) rather than distant (years) leads consumers to take health risks more seriously (Kees, 2011). Although a distant time frame increases the 'unknown' nature of a risk, Kees' result likely relates to the public's perception that an 
event presently framed (e.g., 'every day') is more likely to occur (and provokes more concern) than when the same event is future framed (e.g., 'every year'; Chandran \& Menon, 2004). This highlights, once again, the multidimensionality of risk perceptions.

Problematically, time frame between exposure to the hazard and impact may be delayed, as is the case for effects associated with food colouring or pesticides (Fischhoff et al., 1978). This delay could affect both risk management efforts and public acceptance of these efforts, given that the causal relation between the hazard and its effects will be less apparent. Furthermore, according to construal level theory, future and present events are construed differently, with those in the present construed in more concrete terms than those in the future (Trope \& Liberman, 2003). As concrete construals carry more affective value (Trope \& Liberman, 2003), it is unsurprising that the public perceive events with immediate consequences as serious (Fife-Schaw \& Rowe, 1996).

\section{Involuntary nature of exposure.}

The public is reported to be a thousand times more worried about involuntary risks compared to voluntary ones (Slovic, 1987; Starr, 1969), leading to increased risk perceptions and reduced acceptance levels (Fox-Glassman \& Weber, 2016). This characteristic relates to the extent to which one chooses to expose oneself to a risk (Barnett \& Breakwell, 2001). Whilst there is no clear, objective distinction between voluntary and involuntary risks (Barnett \& Breakwell, 2001), the latter are generally considered as those which one is exposed to without prior consent or knowledge, and which are thus uncontrollable.

The involuntary nature of a hazard characteristic is typically found to load on the dread factor (Savadori et al., 2004; Siegrist et al., 2006). This may in part be because involuntary risks are, by definition, less controllable. In contrast, risks that are voluntary tend to be judged by the public as more well-known, controllable, and non-catastrophic (Fischhoff et al., 1978; Slovic, 1987). Indeed, controllability is associated with public risk perceptions (Finucane, Slovic, et al., 2000; Fischhoff et al., 1978; Siegrist et al., 2008; Slovic et al., 1986). For instance, individuals are less worried about food hygiene standards inside the home than outside of the home (Miles et al., 2004).

As well as risk perceptions, levels of concern have also been shown to vary between involuntary versus voluntary food risks. More concern is associated with eating food containing food colouring, or which has been genetically engineered - instances where it may not be clear that the food contains/involves these risks (Barnett \& Breakwell, 2001). Indeed, the strength of public feeling regarding the horsemeat scandal can be related to the involuntary, and unknowable, nature of what was being consumed.

\section{Implications and recommendations.}

When identifying the population exposed to a risk, there may be different thresholds for making particular risk management decisions for different populations. For instance, if children are at risk, 
one might want lower thresholds regarding, for instance, permissible levels/ maximum residue limits, even beyond those dictated by biology, due to a desire to mitigate risk further.

Given the phenomenon of 'psychophysical numbing', risk managers' mitigation decisions are unlikely to be appropriately sensitive to the numbers of people exposed. When expressing estimates about the proportion of the population exposed or the time frame for a hazard's effects, risk assessors should use a consistent format (e.g., percentage) and units (e.g., days). This will guard against unintended effects of presentation format on public understanding of the same objective risk.

Finally, the public's risk perceptions have been shown to differ according to the voluntariness of exposure. A risk may be characterised as higher when exposure is involuntary versus voluntary. A risk manager's threshold for action may correspondingly also be lower in the former instance.

\section{Risk Characterisation}

Risk characterisation is the final process of integrating data from the previous three components of the risk assessment, resulting in an estimation of the probability of occurrence and severity of adverse health effects in a given population (WHO/FAO, 2015). The resulting statement of the harm associated with the hazard used in the communication of the risk characterisation from the risk assessor to the risk manager may be qualitative, in the form of an evaluative label (e.g., high, medium, low) or a verbal probability expression (e.g., 'likely'), or quantitative, in the form of a numerical estimate of risk, such as a health based guidance value (WHO/FAO, 2009) like acceptable daily intake (ADI) (Renwick et al., 2003). Although quantitative estimates are preferable and should be provided where possible (Benford et al., 2018), high levels of uncertainty, insufficient time and/or data may mean qualitative statements are the only way of characterising risk (CAC, 1999, Section 2). Furthermore, even when sufficient quantitative data exists, this information may still be presented qualitatively.

For the purposes of this review, we use the terms qualitative and quantitative in a similar way to EFSA. According to EFSA (Benford et al., 2018), the expression of uncertainty requires two components: (1) the range of possible true answers to a question or quantity of interest, (2) the probability of different answers or values ${ }^{3}$. Uncertainty expressions for both of these components can be categorised as either quantitative or qualitative. An awareness of the possible variance in interpretations of these expressions is vital given the potential for different decisions (see also, Hart et al., 2019). Appropriate risk characterisation is therefore key to informing effective risk management decisions.

\footnotetext{
${ }^{3}$ We acknowledge that the research in the following is predominantly about likelihood, rather than a combination of likelihood and severity (as per the CAC [2015] definition of risk). This was not intentional, but resulted from the focus of the existing literature.
} 


\section{Qualitative characterisation.}

Risk can be characterised qualitatively where data is inadequate for specific numerical estimates, but allows for ranking or separation into distinct risk categories (CAC, 1999, Section 2). These descriptive categories are often in the form of evaluative labels, such as high, low or negligible risk, which reflect a 'holistic evaluation' of the option (Peters et al., 2009). Labels are perceived by the public as easier and less effortful to use (versus numerical ranges) (Dieckmann et al., 2012) and indeed hold certain advantages. For instance, labels aid the evaluation of unfamiliar, or not easily evaluable, numerical information - one can easily rank hazards on the basis of their labels (Dieckmann et al., 2012). They have also been shown to improve the public's utilisation of unfamiliar numerical information (Peters et al., 2009), attributed to the fact that labels highlight specific information.

The ability to highlight information which might otherwise be missed is clearly useful, but doing so may also have (unintended) deleterious effects. Dieckmann et al. (2012) suggest that highlighting specific information may lead the public to over-inflate its importance and thus overweight it in decision-making. Furthermore, labels may not always convey all the necessary information for a decision - such as upper and lower bounds (as expressed explicitly in a quantitative range). Indeed, studies have shown that despite labels being perceived as easier to use, laypeople were worse at identifying the likelihood of a particular value (versus performance given a range) (Dieckmann et al., 2012).

There is also clear potential for variation in understanding given use of labels (Hubbard, 2015). Use of labels (e.g., 'low') to present test results was associated with a greater proportion of misunderstandings than when test results were presented using numerical probabilities (Marteau et al., 2000). When labels such as 'common' or 'uncommon' were used, patients significantly overestimated the likelihood of side effects of a medication, leading to higher risk perceptions and reduced likelihood of taking the medication (Berry et al., 2003). Interpretations of labels have also been found to be significantly influenced by contextual factors, with little expert agreement on the category boundaries of labels (Hilton et al., 2008). It is therefore unsurprising that Dieckmann et al. (2012) recommended making the processes by which labels are given to certain levels, and the thresholds for each category, explicit. They also warned that if specific parameter values are important, labels should be used with caution.

\section{Verbal probability expressions.}

Verbal probability expressions (VPEs) classify a risk into a category of likelihood (e.g., COT report on BPA, 2014). VPEs (e.g., 'not likely', 'likely') are useful because they openly acknowledge uncertainty and refer to a range of probabilities (e.g., Budescu \& Wallsten, 1995). Yet VPEs' imprecision is also their weakness. Considerable variation in the use and interpretation of these expressions (e.g., Beyth- 
Marom, 1982) means that the potential for miscommunication is high. Interpretations have also been shown to be vulnerable to a range of contextual and cultural influences (e.g. Harris et al., 2013; Weber \& Hilton, 1990). Such influences can lead to increased risk perceptions (Weber \& Hilton, 1990) and leave a communicator vulnerable to a loss in credibility (Jenkins et al., 2019). Of particular note is the finding that VPEs have been shown to influence risk management decisions. Doyle et al. (2014) found that fewer scientists and laypeople suggested evacuating when the risk of a volcanic eruption was described using verbal terms than when using numerically equivalent (range) terms, with a greater effect seen for scientists compared to laypeople. The effect was attributed to the greater perceived certainty of numerical terms, suggesting the need for immediate action.

A further characteristic, which is not always immediately obvious when using VPEs, is the fact that VPEs convey additional information, over and above communicating likelihood. VPEs are directional, in that they focus one's attention on either the occurrence (positive directionality, e.g., 'likely') or the non-occurrence of an event (negative directionality, e.g., 'unlikely') (e.g., Teigen \& Brun, 1995, 1999). Even where terms are interpreted as conveying the same numerical probability, differences in directionality lead to different predictions, recommendations and decisions of laypeople (Honda \& Yamagishi, 2009; Teigen \& Brun, 1999). For instance, if the likelihood of side effects from a medication is described as 'quite uncertain', greater intentions to take the medication are observed than when there is 'some possibility' of side effects (Teigen \& Brun, 1999). In addition to decisions, directionality has also been shown to influence perceived certainty, such that an outcome described using a negatively (positively) directional VPE was perceived as less (more) certain (Honda \& Yamagishi, 2009). If VPEs are used, then their directionality should be kept consistent (see also Hart et al., 2019).

\section{Quantitative characterisation.}

Where the data allow, risk can be expressed numerically (CAC, 1999). The precise type of quantitative output is ultimately the choice of the risk assessor but will, in part, depend on the type of hazard. Point estimates, for instance, are typically the output of chemical risk assessments, and probabilistic outputs (using probability distributions) the result of microbiological risk assessments. These outputs may be, for instance, a quantitative estimate of risk associated with exposure, or advice on specific levels which are safe or maximally acceptable. Numerical expressions would appear to be advantageous for both the public and experts, in that they are more precise than qualitative terms, have a clear, fixed-rank order (e.g., $90 \%$ is more than $70 \% ; 1.5 \mathrm{mg}$ is twice as much as $0.75 \mathrm{mg}$ ) and can easily be translated to other formats (e.g., $20 \%$ is equivalent to 1 in 5 ). 


\section{Point estimates.}

Numerical point estimates can be used to describe outcomes (e.g., an ADI of $1 \mathrm{mg}$ ) as well as probability (e.g., 1\% likelihood). There has been a paradigmatic shift away from the use of point estimates in risk analysis across many domains, including the environment, transport, and food safety. Such a shift has resulted from the criticism of point estimates as 'a gross simplification', and the fact that they ignore important dynamics such as variability and uncertainty (Thompson, 2002). Furthermore, Thompson (2002) has argued that the previous proliferation of point estimates has given the public the incorrect impression that risk assessors are able to estimate risks with far more precision than is actually possible, which, as seen below, is problematic. As the majority of research investigating point estimates has done so in conjunction with range estimates, much of the work concerning point estimates is included in the 'ranges' section.

On the face of it, point estimates seem advantageous for risk assessors, given they are claimed to be 'psychologically easier', as there are fewer possible outcomes to consider, which makes them less cognitively demanding than ranges (Joslyn et al., 2013). In addition, given that precision is associated with expertise (Jerez-Fernandez et al., 2014), it could be presumed that the public will also have more confidence in point estimates.

However, laypersons' perceptions of point estimates are not always positive, which may result from them being seen as overly deterministic in implying only a single outcome (Joslyn \& Grounds, 2015), and giving an (artificial) impression of certainty (Han et al., 2009). In being so precise, they become 'paradoxically more ambiguous' (Han et al., 2009) and thus more concerning, because the public ask which factors have not been sufficiently accounted for in the estimate (Joslyn \& Savelli, 2010) and attempt to correct for these (Grounds et al., 2017; Joslyn et al., 2011). For these individuals, a point estimate is perceived as more risky than a range because it does not seem credible (Han et al., 2009).

The fact that perceptions of point estimates are not always favourable is problematic for communicators, given it is generally accepted that decision makers (and thus risk managers/policy makers) are sensitive to, and prefer, precise over imprecise options (e.g., Ellsberg, 1961). Importantly for risk assessors, according to the congruence principle (Budescu \& Wallsten, 1995), the precision of the uncertainty information should match the degree of certainty which can be expected for estimates about the event. For instance, it is not necessarily appropriate to use a point estimate to describe, for example, the number of pathogens found in raw chicken, which might not be so precisely quantifiable. If such precision is perceived as excessive, it can negatively impact on understanding and trust in the estimate, a pattern seen in laypeople (Han et al., 2009). 


\section{Ranges.}

Use of ranges may arise as a result of a potential lack of data, or lack of consensus. Ranges are especially useful given prescriptions to include clear explanations of the nature and magnitude of any uncertainties within a risk characterisation (Renwick et al., 2003). For clarity, we first consider evidence pertaining to the expression of uncertainty in assessments of numerical probability ranges (e.g., $10-30 \%$ likelihood, as low as 1 in 100,000 or as high as 1 in 10,000), before focusing on the expression of uncertainty in outcomes (e.g., ADI of $0.5-2.5 \mathrm{mg}$ ).

\section{Probability ranges.}

The widespread use of probability ranges is based on the assumption that they reflect the (im)precision in an estimate, as well as indicating the range of possible future states (Dieckmann et al., 2015). Research regarding the public's understanding and perception of probability ranges is, however, mixed. There is some evidence to indicate that probability ranges provide no benefit over point estimates for increasing the public's understanding, with similar understanding of medication side effects observed for both formats (Moraes \& da Silva Dal Pizzol, 2018). Conversely, Longman et al. (2012) observed that students displayed reduced understanding with range estimates (including both narrow and wide), as opposed to point estimates. The wide range was also perceived as riskier compared to the point and narrow range estimates. Sladakovic et al. (2015) also found students showed reduced understanding when harm and benefit information was presented in a range, rather than point, format. Format also influenced behavioural intentions. When the level of uncertainty decreased (i.e., harm and benefit information was first presented as a range, and subsequently a point estimate), intentions to take medication for a migraine increased. Increased public risk perceptions have also been found to be accompanied by greater worry (Han et al., 2009). One possible explanation for these increased risk perceptions is the higher (and more variable) perceived likelihoods for range estimates (Dieckmann et al., 2010), as well as the potential tendency to focus on the upper limit of the range as a 'worst case scenario' (Han et al., 2009). Such a focus on the upper limit of the range (related to the precautionary principle) might lead to more conservative risk management decisions than were one to focus on the complete range. Other studies investigating lay perceptions have not however seen increased levels of perceived risk for range (versus point) formats (Han et al., 2011; Jenkins et al., 2019), though Han et al. did observe increased levels of worry with ranges.

It has been suggested that being open about uncertainty may lead to enhanced credibility in the eyes of the public, with communicators using ranges perceived as more honest, yet still competent (Johnson \& Slovic, 1995). However, the evidence for such a suggestion is mixed, with use of ranges associated with doubts over the communicator's level of knowledge and negative effects on perceived credibility (relative to point estimates) (Han et al., 2009). However, other studies with laypeople have 
found range estimates and point estimates are perceived as equally credible (Jenkins et al., 2019), trustworthy, accurate and personally relevant (Lipkus et al., 2001).

\section{Outcome ranges.}

There are several types of outcome ranges identified in the literature, such as confidence intervals and predictive intervals, which likely contributes to the mixed results regarding the public's comprehension and perception of them. Confidence intervals are a range of values which are likely to contain the true population mean (e.g., if a $95 \%$ confidence interval is 10 to 25 ppm - one can be $95 \%$ confident that the mean of, for instance, additive $X$ in food product $Y$ lies within this range). Predictive intervals relate to where a value will fall in the future and inform one of the distribution of values (e.g., $95 \%$ confident that 5 to $35 \mathrm{ppm}$ includes the level of additive $X$ in the next batch of food product $Y$ ). Prediction intervals are always wider than confidence intervals.

In the context of decision-making, predictive intervals have been found to allow laypeople to better distinguish between situations when precautionary action should and should not be taken, such that decision makers receiving predictive intervals are more decisive than those who see point estimates (e.g., Grounds et al., 2017; Joslyn et al., 2013). This has been attributed to the fact that a predictive interval forecast narrows expectations of which outcomes will occur, with laypeople recognising the decreased likelihood of outcomes beyond the range boundary (Grounds et al., 2017; Joslyn et al., 2013). In addition, compared to a point, or point plus an upper bound estimate, provision of the whole range improved lay understanding. As an example, where only a point plus an upper bound estimate were provided, participants anchored their estimates towards the upper bound and took overly precautionary actions (relative to an expected value calculation). Such tendencies were reduced with provision of the whole range (Joslyn et al., 2011).

In addition to improving decision-making, the use of outcome ranges is also positively received. Joslyn and colleagues found the public had greater levels of trust in a forecast using a predictive interval versus a point format (Joslyn et al., 2013; Joslyn \& LeClerc, 2016), with those who saw the predictive interval also more likely to choose to receive such a format of forecast again (Joslyn et al., 2013).

When using outcome ranges, it is important to specify how such ranges are to be interpreted. Research has documented problems in the understanding of outcome ranges, with variability in laypeople's interpretations of the probability distribution underlying the numerical range (e.g., whether it was normal, uniform or u-shaped) (Dieckmann et al., 2015). Such interpretations have been shown to be influenced by the motivations and world view of the user (Dieckmann et al., 2017). This could have unintended effects on risk management decisions. If a numerical range is interpreted as referring to a uniform distribution, one will weigh the information differently than if it is interpreted 
as reflecting a normal distribution, and may be more likely to take action in the former instance, on the basis that all values are equally likely. However, the effect of motivation and world view only occurred when it was unclear how to interpret the information (e.g., no label/graph stating the normal distribution of outcomes) (Dieckmann et al., 2017). In addition, the provision of a best estimate increased perceptions of a normal distribution (Dieckmann et al., 2015).

Further evidence for the importance of clarifying how outcome ranges, specifically 'predictive intervals', should be interpreted comes from the work of Joslyn and colleagues. When laypeople were presented with a temperature forecast visualisation, $15 \%$ of participants perceived the upper (lower) bound as denoting the daytime high (low) temperature, termed the 'deterministic construal error' (DCE), an error which was far more common than with a point forecast (e.g., Grounds et al., 2017; Joslyn et al., 2013). Somewhat surprisingly, there is some evidence that the effect only appears when the intervals are presented with a visualisation (Grounds et al., 2017), although this result requires further investigation.

The understanding of outcome ranges (specifically relating to level of uncertainty) may further be improved with the addition of labels. There is mixed evidence regarding whether laypeople understand that the width of a range is associated with the uncertainty of an estimate (Dieckmann et al., 2012). However, when explicitly asked to identify the option with the greatest amount of attribute uncertainty, performance was improved when an evaluative label (e.g., 'high', 'low') was presented with the range (Dieckmann et al., 2012).

When using outcome ranges, communicators should also take into account the audience, given that inter-individual variability in interpretations has been observed between experts and laypeople (Gregory et al., 2012). The two groups make different decisions when presented with numerical range information: laypeople typically selected the option with the most favourable best estimate, but lowest confidence, whereas experts more often selected the 'compromise' option. This pattern of results might reflect experts' focus on the width of the range as an indicator of the uncertainty in the estimate, with laypeople focusing on the best/worst case scenario. Such a difference could also explain why laypeople indicated that decision-making was harder and more effortful with the range format (versus an evaluative label e.g., 'high' or 'excellent') (Gregory et al., 2012).

Finally, it is important to consider the language one uses when presenting outcome ranges. For example, the outcome range '0.5-2.5 mg' may also be described using expressions such as 'more than $0.5 \mathrm{mg}$ '/'above $0.5 \mathrm{mg}$ ' (lower bounds) or 'less than $2.5 \mathrm{mg}^{\prime} /$ 'below $2.5 \mathrm{mg}$ ' (upper bounds), with the former expressions more frequently used (Halberg \& Teigen, 2009). Whilst one might presume these to be similar ways of framing the same estimate, the bounds act as reference points (Halberg \& 
Teigen, 2009), conveying additional pragmatic information suggesting how the magnitude should be interpreted or evaluated. For instance, the expressions may be used by the speaker to convey attitudes or expectations, or to encourage a certain course of action. The expressions are directional, in that they guide one's attention to either the occurrence (lower), or non-occurrence (upper) of an event (Hohle \& Teigen, 2018). Studies with laypeople have shown that these expressions also indicate a communicator's belief about whether the trend will increase or decrease (Hohle \& Teigen, 2018). Generally, lower (upper) bounds are perceived as indicating large, increasing (small, decreasing) quantities (Teigen, 2008). Clearly, single bound range estimates are not synonyms for full numerical ranges, and should not be treated as such in risk assessments.

\section{Implications and recommendations.}

The evidence regarding qualitative expressions demonstrates that interpretations of evaluative labels and VPEs are highly variable. Much of this research was in relation to laypeople's understanding of such expressions. However, the ambiguity of such expressions means that even experts will show considerable variability in interpretations, and thus their use by risk assessors has clear potential to influence risk management decisions (Hubbard, 2015). We therefore suggest that risk assessors and risk managers should use such terms to characterise food risks with caution; a sentiment voiced by EFSA (Benford et al., 2018). When characterising a risk, wherever possible, use of VPEs (e.g., 'unlikely') and evaluative labels (e.g., 'low risk') should be avoided. If they are used, Dieckmann et al. (2012) recommend making the processes by which labels are given to certain levels, and the thresholds for each category, explicit. Relatedly, risk assessors should be mindful of how they phrase outcomes. Risk managers might be more inclined to take action, and make more precautionary decisions, if outcomes are phrased as having ' $\mathrm{X} \%$ certainty' versus having an ' $\mathrm{X} \%$ probability'.

The research relating to quantitative expressions suggests clear advantages over qualitative expressions. However, although quantitative expressions are more precise, they are not infallible their use is not enough to guarantee accurate or consistent interpretation (Dieckmann et al., 2015). Increased precision of a communication (e.g., point vs. range) does not always equate to greater understanding. Rather, the precision of the communication should correspond to the level of certainty which can be expected. Risk assessors (and managers) may therefore choose to use a range estimate, which can better reflect the associated uncertainties. If a numerical range is used, risk analysts should provide detailed descriptions as to how it should be interpreted, for instance what type of distribution (e.g., uniform or normal) it refers to. Relatedly, ranges may be better understood when accompanied by a 'best estimate' (Dieckmann et al., 2015). 


\section{Implications}

As food technology and production processes continue to evolve, new risks will arise, which must be assessed and managed. The aim of this review was to consider factors which could influence how risks are assessed and characterised. Whilst our focus was ostensibly on the risk assessment stage of risk analysis, these factors have downstream consequences for risk management and communication efforts. Moreover, because of the interactive nature of the relationship between the three stages (WHO/FAO, 2006, 2009), the reviewed research is relevant to all three components of risk analysis.

Drawing on insights from the psychological literature, we make some initial practical recommendations to standardise approaches at the exposure assessment and risk characterisation stages. When providing an exposure assessment, the proportion of the population exposed or the time frame for the effects of the hazard should be expressed consistently, using the same format (e.g., as a percentage) or the same units (e.g., in terms of days). When characterising risks, assessors should, wherever possible, try to avoid use of qualitative expressions such as evaluative labels or VPEs, given the variability in their interpretation (a recommendation currently shared by EFSA, Benford et al., 2018). If they are to be used, then assessors should keep the directionality of VPEs consistent. When using quantitative expressions, the precision of a communication should match the level of certainty which can be expected. If ranges are used, then clarification should be given as to the type of distribution it refers to. Provision of a 'best estimate' may also improve understanding.

Additionally, this review has highlighted a number of factors which could be used as a basis for improving the efficacy of the wider risk analysis process. Knowledge of the factors which influence levels of perceived risk and concern for a hazard means that risk management and communication efforts could be tailored accordingly. For instance, if a hazard is perceived as lacking in benefits, then a risk communication might seek to highlight benefits for consumers.

Overall, this review has challenged the 'objective' view of risk traditionally implicit within technical risk assessment. Acknowledging the psychological processing of risk within risk assessment is the first step towards developing and testing complementary risk assessment strategies. Risk analysis must acknowledge and work with the subjectivity of risk if experts and the public are to be well equipped to make informed and effective decisions. 


\section{References}

Alhakami, A. S., \& Slovic, P. (1994). A psychological study of the inverse relationship between perceived risk and perceived benefit. Risk Analysis, 14(6), 1085-1096. https://doi.org/10.1111/j.1539-6924.1994.tb00080.x

Barnett, J., \& Breakwell, G. M. (2001). Risk perception and experience: hazard personality profiles and individual differences. Risk Analysis, 21(1), 171-178. https://doi.org/10.1111/02724332.211099

Benford, D., Halldorsson, T., Jeger, M. J., Knutsen, H. K., More, S., Naegeli, H., Noteborn, H., Ockleford, C., Ricci, A., Rychen, G., Schlatter, J. R., Silano, V., Solecki, R., Turck, D., Younes, M., Craig, P., Hart, A., Von Goetz, N., Koutsoumanis, K., ... Hardy, A. (2018). The principles and methods behind EFSA's Guidance on Uncertainty Analysis in Scientific Assessment. EFSA Journal, 16(1), 1-39. https://doi.org/10.2903/j.efsa.2018.5123

Berry, D. C., Raynor, D. K., Knapp, P., \& Bersellini, E. (2003). Patients' understanding of risk associated with medication use: Impact of european commission guidelines and other risk scales. Drug Safety, 26(1), 1-11. https://doi.org/10.2165/00002018-200326010-00001

Beyth-Marom, R. (1982). How probable is probable? A numerical translation of verbal probability expressions. Journal of Forecasting, 1(3), 257-269. https://doi.org/10.1002/for.3980010305

Budescu, D. V, \& Wallsten, T. S. (1995). Processing linguistic probabilities: General principles and empirical evidence. Psychology of Learning and Motivation, 32(2), 275-318. https://doi.org/http://doi.org/10.1016/S0079-7421(08)60313-8

Cardello, A. V. (2003). Consumer concerns and expectations about novel food processing technologies: effects on product liking. Appetite, 40(3), 217-233. https://doi.org/10.1016/S0195-6663(03)00008-4

Chandran, S., \& Menon, G. (2004). When a day means more than a year: Effects of temporal framing on judgments of health risk. Journal of Consumer Research, 31(2), 375-389. https://doi.org/10.1086/422116

Codex Alimentarius Commission (CAC). (1999). Principles and guidelines for the conduct of microbiological risk assessment (CAC/GL 30-1999). http://www.fao.org/docrep/004/y1579e/y1579e05.htm

Committee on Toxicity of Chemicals in Food Consumer Products and the Environment (COT). (2014). COT response to the EFSA Consultation on a draft scientific opinion on the risks to public health related to the presence of bisphenol $A(B P A)$ in foodstuffs Secretariat. https://cot.food.gov.uk/sites/default/files/cot/tox201415.pdf

Cunha, L. M., de Moura, A. P., Lopes, Z., do Céu Santos, M., \& Silva, I. (2010). Public perceptions of food-related hazards: an application to Portuguese consumers. British Food Journal, 112(5), 
522-543. https://doi.org/10.1108/00070701011043772

Dieckmann, N., Gregory, R., Peters, E. M., \& Hartman, R. (2017). Seeing what you want to see: how imprecise uncertainty ranges enhance motivated reasoning. Risk Analysis, 37(3), 471-486. https://doi.org/10.1111/risa.12639

Dieckmann, N., Mauro, R., \& Slovic, P. (2010). The effects of presenting imprecise probabilities in intelligence forecasts. Risk Analysis, 30(6), 987-1001. https://doi.org/10.1111/j.15396924.2010.01384.x

Dieckmann, N., Peters, E. M., \& Gregory, R. (2015). At home on the range? Lay interpretations of numerical uncertainty ranges. Risk Analysis, 35(7), 1281-1295.

https://doi.org/10.1111/risa.12358

Dieckmann, N., Peters, E. M., Gregory, R., \& Tusler, M. (2012). Making sense of uncertainty: Advantages and disadvantages of providing an evaluative structure. Journal of Risk Research, 15(7), 717-735. https://doi.org/10.1080/13669877.2012.666760

Doyle, E. E. H., McClure, J., Paton, D., \& Johnston, D. M. (2014). Uncertainty and decision making: Volcanic crisis scenarios. International Journal of Disaster Risk Reduction, 10, 75-101. https://doi.org/10.1016/j.ijdrr.2014.07.006

EFSA Scientific Committee. (2012). Scientific Opinion on Risk Assessment Terminology. EFSA Journal, 10(5), 2664. https://doi.org/10.2903/j.efsa.2012.2664

Ellsberg, D. (1961). Risk, ambiguity, and the Savage axioms. The Quarterly Journal of Economics, 75(4), 643. https://doi.org/10.2307/1884324

European Commission Scientific Committee for Food. (1997). Opinion on principles for the development of risk assessment of microbiological hazards under the hygiene of foodstuffs directive. https://ec.europa.eu/food/sites/food/files/safety/docs/sci-com_scf_7_out07_en.pdf

European Food Safety Authority. (2019). Glossary. https://www.efsa.europa.eu/en/glossarytaxonomy-terms

European Food Safety Authority. (2020). EFSA Strategy 2020: Trusted science for safe food. https://doi.org/10.2805/397609

Fechner, G. T. (1966). Elements of psychophysics. Holt, Rinehart \& Winston.

Fetherstonhaugh, D., Slovic, P., Johnson, S. M., \& Friedrich, J. (1997). Insensitivity to the value of human life: A study of psychophysical numbing. Journal of Risk and Uncertainty, 14(3), 283300. https://doi.org/10.1023/A:1007744326393

Fife-Schaw, C., \& Rowe, G. (1996). Public perceptions of everyday food hazards: A psychometric study. Risk Analysis, 16(4), 487-500. https://doi.org/10.1111/j.1539-6924.1996.tb01095.x

Fife-Schaw, C., \& Rowe, G. (2000). Research Note: Extending the application of the psychometric approach for assessing public perceptions of food risk: some methodological considerations. 
Journal of Risk Research, 3(2), 167-179. https://doi.org/10.1080/136698700376653

Finucane, M. L., Alhakami, A., Slovic, P., \& Johnson, S. M. (2000). The affect heuristic in judgments of risks and benefits. Journal of Behavioral Decision Making, 13(1), 1-17. https://doi.org/10.1002/(SICI)1099-0771(200001/03)13:1<1::AID-BDM333>3.0.CO;2-S

Finucane, M. L., Slovic, P., \& Mertz, C. K. (2000). Public perception of the risk of blood transfusion. Transfusion, 40(8), 1017-1022. https://doi.org/10.1046/j.1537-2995.2000.40081017.x

Fischer, A., \& De Vries, P. W. (2008). Everyday behaviour and everyday risk: An approach to study people's responses to frequently encountered food related health risks. Health, Risk and Society, 10(4), 385-397. https://doi.org/10.1080/13698570802166449

Fischhoff, B., Slovic, P., Lichtenstein, S., Read, S., \& Combs, B. (1978). How safe is safe enough? A psychometric study of attitudes towards technological risks and benefits. Policy Sciences, 9(2), 127-152. https://doi.org/10.1007/BF00143739

Fox-Glassman, K. T., \& Weber, E. U. (2016). What makes risk acceptable? Revisiting the 1978 psychological dimensions of perceptions of technological risks. Journal of Mathematical Psychology, 75, 157-169. https://doi.org/10.1016/j.jmp.2016.05.003

Frewer, L. J. (2017). Consumer acceptance and rejection of emerging agrifood technologies and their applications. European Review of Agricultural Economics, 44(4), 683-704. https://doi.org/10.1093/erae/jbx007

Frewer, L. J., Fischer, A., Brennan, M., Bánáti, D., Lion, R., Meertens, R. M., Rowe, G., Siegrist, M., Verbeke, W., \& Vereijken, C. (2016). Risk/benefit communication about food-A systematic review of the literature. Critical Reviews in Food Science and Nutrition, 56(10), 1728-1745. https://doi.org/10.1080/10408398.2013.801337

Frewer, L. J., Howard, C., \& Shepherd, R. (1998). Understanding public attitudes to technology. Journal of Risk Research, 1(3), 221-235. https://doi.org/10.1080/136698798377141

Frewer, L. J., Shepherd, R., \& Sparks, P. (1994). The interrelationship between perceived knowledge, control and risk associated with a range of food-related hazards targeted at the individual, other people and society. Journal of Food Safety, 14(1), 19-40. https://doi.org/10.1111/j.17454565.1994.tb00581.x

Gregory, R., Dieckmann, N., Peters, E. M., Failing, L., Long, G., \& Tusler, M. (2012). Deliberative disjunction: Expert and public understanding of outcome uncertainty. Risk Analysis, 32(12), 2071-2083. https://doi.org/10.1111/j.1539-6924.2012.01825.x

Grounds, M. A., Joslyn, S. L., \& Otsuka, K. (2017). Probabilistic interval forecasts: an individual differences approach to understanding forecast communication. Advances in Meteorology, 118. https://doi.org/10.1155/2017/3932565

Halberg, A.-M., \& Teigen, K. H. (2009). Framing of imprecise quantities: When are lower interval 
bounds preferred to upper bounds? Journal of Behavioral Decision Making, 22(5), 490-509. https://doi.org/10.1002/bdm.635

Han, P. K. J., Klein, W. M. P., Lehman, T. C., Killam, B., Massett, H., \& Freedman, A. N. (2011). Communication of uncertainty regarding individualized cancer risk estimates: effects and influential factors. Medical Decision Making, 31(2), 354-366.

https://doi.org/10.1177/0272989X10371830

Han, P. K. J., Klein, W. M. P., Lehman, T. C., Massett, H., Lee, S. C., \& Freedman, A. N. (2009). Laypersons' responses to the communication of uncertainty regarding cancer risk estimates. Medical Decision Making, 29(3), 391-403. https://doi.org/10.1177/0272989X08327396

Harris, A. J. L., Corner, A., Xu, J., \& Du, X. (2013). Lost in translation? Interpretations of the probability phrases used by the Intergovernmental Panel on Climate Change in China and the UK. Climatic Change, 121(2), 415-425. https://doi.org/10.1007/s10584-013-0975-1

Hart, A., Maxim, L., Siegrist, M., Von Goetz, N., da Cruz, C., Merten, C., Mosbach-Schulz, O., Lahaniatis, M., Smith, A., Hardy, A., Bampidis, V., Benford, D., Boesten, J., Bragard, C., Ingi Halldorsson, T., Hern andez-Jerez, A. F., Hougaard Bennekou, S., Panagiotis Koutsoumanis, K., John More, S., ... Younes, M. (2019). Guidance on communication of uncertainty in scientific assessments. EFSA Journal, 17(1), 5520. https://doi.org/10.2903/j.efsa.2019.5520

Hilton, Z. N., Carter, A. M., Harris, G. T., \& Sharpe, A. J. B. (2008). Does using nonnumerical terms to describe risk aid violence risk communication?: Clinician agreement and decision making. Journal of Interpersonal Violence, 23(2), 171-188. https://doi.org/10.1177/0886260507309337

Hohle, S., \& Teigen, K. H. (2018). More than $50 \%$ or less than $70 \%$ chance: Pragmatic implications of single bound probability estimates. Journal of Behavioral Decision Making, 31(1), 138-150. https://doi.org/10.1002/bdm.2052

Honda, H., \& Yamagishi, K. (2009). Perceived certainty based on verbal probability phrases: Effect of directionality and its dependence on method. Japanese Psychological Research, 51(4), 266273. https://doi.org/10.1111/j.1468-5884.2009.00409.x

Hubbard, D. W. (2015). Worse than useless: the most popular risk assessment method and why it doesn't work. In The Failure of Risk Management: Why It's Broken and How to Fix It (pp. 117143). John Wiley \& Sons, Inc. https://doi.org/10.1002/9781119198536.ch7

Jenkins, S. C., Harris, A. J. L., \& Lark, R. M. (2019). When unlikely outcomes occur: the role of communication format in maintaining communicator credibility. Journal of Risk Research, 22(5), 537-554. https://doi.org/10.1080/13669877.2018.1440415

Jerez-Fernandez, A., Angulo, A. N., \& Oppenheimer, D. M. (2014). Show me the numbers: Precision as a cue to others' confidence. Psychological Science, 25(2), 633-635.

https://doi.org/10.1177/0956797613504301 
Johnson, B. B., \& Slovic, P. (1995). Presenting uncertainty in health risk assessment: Initial studies of its effects on risk perception and trust. Risk Analysis, 15(4), 485-494. https://doi.org/10.1111/j.1539-6924.1995.tb00341.x

Joslyn, S. L., \& Grounds, M. A. (2015). The use of uncertainty forecasts in complex decision tasks and various weather conditions. Journal of Experimental Psychology: Applied, 21(4), 407-417. https://doi.org/10.1037/xap0000064

Joslyn, S. L., \& LeClerc, J. E. (2016). Climate projections and uncertainty communication. Topics in Cognitive Science, 8(1), 222-241. https://doi.org/10.1111/tops.12177

Joslyn, S. L., Nemec, L., \& Savelli, S. (2013). The benefits and challenges of predictive interval forecasts and verification graphics for end users. Weather, Climate, and Society, 5, 133-147. https://doi.org/10.1175/WCAS-D-12-00007.1

Joslyn, S. L., \& Savelli, S. (2010). Communicating forecast uncertainty: Public perception of weather forecast uncertainty. Meteorological Applications, 17(2), 180-195. https://doi.org/10.1002/met.190

Joslyn, S. L., Savelli, S., \& Nadav-Greenberg, L. (2011). Reducing probabilistic weather forecasts to the worst-case scenario: Anchoring effects. Journal of Experimental Psychology: Applied, 17(4), 342-353. https://doi.org/10.1037/a0025901

Kaptan, G., Fischer, A., \& Frewer, L. J. (2017). Extrapolating understanding of food risk perceptions to emerging food safety cases. Journal of Risk Research, 21(8), 996-1018. https://doi.org/10.1080/13669877.2017.1281330

Kees, J. (2011). Advertising framing effects and consideration of future consequences. Journal of Consumer Affairs, 45(1), 7-32. https://doi.org/10.1111/j.1745-6606.2010.01190.x

Keller, C., Siegrist, M., \& Gutscher, H. (2006). The role of the affect and availability heuristics in risk communication. Risk Analysis, 26(3), 631-639. https://doi.org/10.1111/j.15396924.2006.00773.x

Kirk, S. F. L., Greenwood, D., Cade, J. E., \& Pearman, A. D. (2002). Public perception of a range of potential food risks in the United Kingdom. Appetite, 38(3), 189-197. https://doi.org/10.1006/appe.2001.0478

Klinke, A., \& Renn, O. (2002). A new approach to risk evaluation and management: Risk-based, precaution-based, and discourse-based strategies. Risk Analysis, 22(6), 1071-1094. https://doi.org/10.1111/1539-6924.00274

Lipkus, I. M., Klein, W. M. P., \& Rimer, B. K. (2001). Communicating breast cancer risks to women using different formats. Cancer Epidemiology and Prevention Biomarkers, 10(8), 895-898.

Longman, T., Turner, R., King, M., \& McCaffery, K. J. (2012). The effects of communicating uncertainty in quantitative health risk estimates. Patient Education and Counseling, 89(2), 252- 
259. https://doi.org/10.1016/j.pec.2012.07.010

Marteau, T. M., Saidi, G., Goodburn, S., Lawton, J., Michie, S., \& Bobrow, M. (2000). Numbers or words? A randomized controlled trial of presenting screen negative results to pregnant women. Prenatal Diagnosis, 20(9), 714-718. https://doi.org/10.1002/10970223(200009)20:9<714::AID-PD906>3.0.CO;2-4

McDaniels, T. L. (1998). Ten propositions for untangling descriptive and prescriptive lessons in risk perception findings. Reliability Engineering and System Safety, 59(1), 129-134. https://doi.org/10.1016/S0951-8320(97)00133-6

Miles, S., Brennan, M., Kuznesof, S., Ness, M., Ritson, C., \& Frewer, L. J. (2004). Public worry about specific food safety issues. British Food Journal, 106(1), 9-22. https://doi.org/10.1108/00070700410515172

Miles, S., \& Frewer, L. J. (2001). Investigating specific concerns about different food hazards. Food Quality and Preference, 12(1), 47-61. https://doi.org/10.1016/S0950-3293(00)00029-X Moraes, C. G., \& da Silva Dal Pizzol, T. (2018). Effect of different formats for information on side effects regarding medicine users' understanding: A randomized controlled trial. Patient Education and Counseling, 101(4), 672-678. https://doi.org/10.1016/j.pec.2017.11.015

Ohtsubo, H., \& Yamada, Y. (2007). Japanese public perceptions of food-related hazards. Journal of Risk Research, 10(6), 805-819. https://doi.org/10.1080/13669870701342777

Peters, E. M., Dieckmann, N., Västfjäll, D., Mertz, C. K., Slovic, P., \& Hibbard, J. H. (2009). Bringing meaning to numbers: The impact of evaluative categories on decisions. Journal of Experimental Psychology: Applied, 15(3), 213-227. https://doi.org/10.1037/a0016978

Renwick, A. G., Barlow, S. M., Hertz-Picciotto, I., Boobis, A. R., Dybing, E., Edler, L., Eisenbrand, G., Greig, J. B., Kleiner, J., Lambe, J., Müller, D. J. G., Smith, M. R., Tritscher, A., Tuijtelaars, S., Van Den Brandt, P. A., Walker, R., \& Kroes, R. (2003). Risk characterisation of chemicals in food and diet. Food and Chemical Toxicology, 41(9), 1211-1271. https://doi.org/10.1016/S02786915(03)00064-4

Román, S., Sánchez-Siles, L. M., \& Siegrist, M. (2017). The importance of food naturalness for consumers: Results of a systematic review. Trends in Food Science and Technology, 67, 44-57. https://doi.org/10.1016/j.tifs.2017.06.010

Ronteltap, A., Van Trijp, J. C. M., Renes, R. J., \& Frewer, L. J. (2007). Consumer acceptance of technology-based food innovations: Lessons for the future of nutrigenomics. Appetite, 49, 117. https://doi.org/10.1016/j.appet.2007.02.002

Rowe, G., \& Wright, G. (2001). Differences in expert and lay judgments of risk: myth or reality? Risk Analysis, 21(2), 341-356. https://doi.org/10.1111/0272-4332.212116

Rozin, P. (2006). Naturalness judgments by lay Americans: Process dominates content in judgments 
of food or water acceptability and naturalness. Judgment and Decision Making, 1(2), 91-97. Rozin, P., Fischler, C., \& Shields-Argelès, C. (2012). European and American perspectives on the meaning of natural. Appetite, 59(2), 448-455. https://doi.org/10.1016/j.appet.2012.06.001

Savadori, L., Savio, S., Nicotra, E., Rumiati, R., Finucane, M. L., \& Slovic, P. (2004). Expert and public perception of risk from biotechnology. Risk Analysis, 24(5), 1289-1299.

https://doi.org/10.1111/j.0272-4332.2004.00526.x

Scheer, D., Benighaus, C., Benighaus, L., Renn, O., Gold, S., Röder, B., \& Böl, G. F. (2014). The distinction between risk and hazard: Understanding and use in stakeholder communication. Risk Analysis, 34(7), 1270-1285. https://doi.org/10.1111/risa.12169

Siegrist, M. (2003). Perception of gene technology, and food risks: results of a survey in Switzerland. Journal of Risk Research, 6(1), 45-60. https://doi.org/10.1080/1366987032000047798

Siegrist, M., Cvetkovich, G., \& Roth, C. (2000). Salient value similarity, social trust, and risk/benefit perception. Risk Analysis, 20(3), 353-362. https://doi.org/10.1111/0272-4332.203034

Siegrist, M., Hartmann, C., \& Sütterlin, B. (2016). Biased perception about gene technology: How perceived naturalness and affect distort benefit perception. Appetite, 96, 509-516. https://doi.org/10.1016/j.appet.2015.10.021

Siegrist, M., Keller, C., \& Kiers, H. A. L. (2006). Lay people's perception of food hazards: Comparing aggregated data and individual data. Appetite, 47(3), 324-332.

https://doi.org/10.1016/j.appet.2006.05.012

Siegrist, M., Stampfli, N., Kastenholz, H., \& Keller, C. (2008). Perceived risks and perceived benefits of different nanotechnology foods and nanotechnology food packaging. Appetite, 51(2), 283-290. https://doi.org/10.1016/j.appet.2008.02.020

Siegrist, M., \& Sütterlin, B. (2017). Importance of perceived naturalness for acceptance of food additives and cultured meat. Appetite, 113, 320-326.

https://doi.org/10.1016/J.APPET.2017.03.019

Sirota, M., Juanchich, M., \& Bonnefon, J.-F. (2018). "1-in-X" bias: “1-in-X” format causes overestimation of health-related risks. Journal of Experimental Psychology: Applied, 24(4), 431439. https://doi.org/10.1037/xap0000190

Sjöberg, L. (2000). Perceived risk and tampering with nature. Journal of Risk Research, 3(4), 353-367. https://doi.org/10.1080/13669870050132568

Sjöberg, L. (2001). Limits of knowledge and the limited importance of trust. Risk Analysis, 21(1), 189198. https://doi.org/10.1111/0272-4332.211101

Sjöberg, L. (2002). The allegedly simple structure of experts' risk perception: An urban legend in risk research. Science, Technology, \& Human Values, 27(4), 443-459.

https://doi.org/10.1177/016224302236176 
Sladakovic, J., Jansen, J., Hersch, J., Turner, R., \& McCaffery, K. J. (2015). The differential effects of presenting uncertainty around benefits and harms on treatment decision making. Patient Education and Counseling, 99(6), 1-7. https://doi.org/10.1016/j.pec.2016.01.009

Slovic, P. (1987). Perception of risk. Science, 236(4799), 280-285. https://doi.org/10.1126/science.3563507

Slovic, P. (1999). Trust, emotion, sex, politics, and science: surveying the risk-assessment battlefield. Risk Analysis, 19(4), 689-701. https://doi.org/10.1111/j.1539-6924.1999.tb00439.x

Slovic, P. (2001). The risk game. Journal of Hazardous Materials, 86(1-3), 17-24. https://doi.org/10.1016/S0304-3894(01)00248-5

Slovic, P. (2010). The Feeling of Risk: New Perspectives on Risk Perception. Routledge. https://doi.org/10.4324/9781849776677

Slovic, P., Finucane, M. L., Peters, E. M., \& MacGregor, D. G. (2002). The Affect Heuristic. In T. Gilovich, D. Griffin, \& D. Kahneman (Eds.), Heuristics and Biases (pp. 397-420). Cambridge University Press. https://doi.org/10.1017/CBO9780511808098.025

Slovic, P., Finucane, M. L., Peters, E. M., \& MacGregor, D. G. (2004). Risk as analysis and risk as feelings. Risk Analysis, 24(2), 311-322. https://doi.org/10.1111/j.0272-4332.2004.00433.x Slovic, P., Finucane, M. L., Peters, E. M., \& MacGregor, D. G. (2007). The affect heuristic. European Journal of Operational Research, 177(3), 1333-1352. https://doi.org/10.1016/j.ejor.2005.04.006

Slovic, P., Fischhoff, B., \& Lichtenstein, S. (1982). Facts versus fears: Understanding perceived risk. In D. Kahneman, P. Slovic, \& A. Tversky (Eds.), Judgment under Uncertainty (pp. 463-492). Cambridge University Press. https://doi.org/10.1017/СB09780511809477.034

Slovic, P., Fischhoff, B., \& Lichtenstein, S. (1986). The psychometric study of risk perception. In V. T. Covello, J. Menkes, \& J. Mumpower (Eds.), Risk Evaluation and Management (pp. 3-24). Springer US. https://doi.org/10.1007/978-1-4613-2103-3_1

Slovic, P., Layman, M., Kraus, N., Flynn, J., Chalmers, J., \& Gesell, G. (1991). Perceived risk, stigma, and potential economic impacts of a high-level nuclear waste repository in Nevada. Risk Analysis, 11(4), 683-696. https://doi.org/10.1111/j.1539-6924.1991.tb00658.x

Slovic, P., MacGregor, D. G., Malmfors, T., \& Purchase, I. F. H. (1999). Influence of affective processes on toxicologists' judgments of risk.

Slovic, P., Monahan, J., \& MacGregor, D. G. (2000). Violence risk assessment and risk communication: The effects of using actual cases, providing instruction, and employing probability versus frequency formats. Law and Human Behavior, 24(3), 271-296. https://doi.org/10.1023/A:1005595519944

Slovic, P., \& Peters, E. M. (2006). Risk perception and affect. Current Directions in Psychological 
Science, 15(6), 322-325. https://doi.org/10.1111/j.1467-8721.2006.00461.x

Slovic, P., \& Weber, E. U. (2002). Perception of risk posed by extreme events. Conference on Risk Management Strategies in an Uncertain World, 1-21. https://doi.org/10.1017/CBO9781107415324.004

Sparks, P., \& Shepherd, R. (1994). Public perceptions of the potential hazards associated with food production and food consumption: an empirical study. Risk Analysis, 14(5), 799-806. https://doi.org/10.1111/j.1539-6924.1994.tb00291.x

Starr, C. (1969). Social benefit versus technological risk. Science, 165(3899), 1232-1238. https://doi.org/10.1126/science.165.3899.1232

Teigen, K. H. (2008). More than $X$ is a lot: Pragmatic implicatures of one-sided uncertainty intervals. Social Cognition, 26(4), 379-400. https://doi.org/10.1521/soco.2008.26.4.379

Teigen, K. H., \& Brun, W. (1995). Yes, but it is uncertain: Direction and communicative intention of verbal probabilistic terms. Acta Psychologica, 88(3), 233-258. https://doi.org/10.1016/00016918(93)E0071-9

Teigen, K. H., \& Brun, W. (1999). The directionality of verbal probability expressions: Effects on decisions, predictions, and probabilistic reasoning. Organizational Behavior and Human Decision Processes, 80(2), 155-190. https://doi.org/10.1006/obhd.1999.2857

Thompson, K. M. (2002). Variability and uncertainty meet risk management and risk communication. Risk Analysis, 22(3), 647-54. https://doi.org/10.1111/0272-4332.00044

Trope, Y., \& Liberman, N. (2003). Temporal construal. Psychological Review, 110(3), 403-421. https://doi.org/10.1037/0033-295X.110.3.403

van Kleef, E., Frewer, L. J., Chryssochoidis, G. M., Houghton, J. R., Korzen-Bohr, S., Krystallis, T., Lassen, J., Pfenning, U., \& Rowe, G. (2006). Perceptions of food risk management among key stakeholders: Results from a cross-European study. Appetite, 47(1), 46-63. https://doi.org/10.1016/j.appet.2006.02.002

Weber, E. U., \& Hilton, D. J. (1990). Contextual effects in the interpretations of probability words: Perceived base rate and severity of events. Journal of Experimental Psychology: Human Perception and Performance, 16(4), 781-789. https://doi.org/10.1037/0096-1523.16.4.781

Webster, K., Jardine, C., Cash, S. B., \& McMullen, L. M. (2010). Risk ranking: Investigating expert and public differences in evaluating food safety hazards. Journal of Food Protection, 73(10), 18751885. https://doi.org/10.4315/0362-028X-73.10.1875

World Health Organization/ Food and Agricultural Organization of the United Nations. (2006). Food safety risk analysis - A guide for national food safety authorities.

World Health Organization/ Food and Agricultural Organization of the United Nations. (2009). Chapter 7: Risk Characterization. In Principles and Methods for the Risk Assessment of 
Chemicals in Food. World Health Organization.

World Health Organization/ Food and Agricultural Organization of the United Nations. (2015). Codex Alimentarius Commission Procedural Manual - Twenty Fourth Edition.

Wright, G., Bolger, F., \& Rowe, G. (2002). An empirical test of the relative validity of expert and lay judgments of risk. Risk Analysis, 22(6), 1107-1122. https://doi.org/10.1111/1539-6924.00276

Wright, G., Bolger, F., \& Rowe, G. (2009). Expert judgement of probability and risk. In T. M. Williams, K. Samset, \& K. J. Sunnevåg (Eds.), Making Essential Choices with Scant Information (pp. 213229). Palgrave Macmillan UK. https://doi.org/10.1057/9780230236837_11

Yamagishi, K. (1997). When a $12.86 \%$ mortality is more dangerous than $24.14 \%$ : implications for risk communication. Applied Cognitive Psychology, 11(6), 495-506.

https://doi.org/10.1002/(SICI)1099-0720(199712)11:6<495::AID-ACP481>3.0.CO;2-J 
Table 1. Summary of Review.

\begin{tabular}{|c|c|c|}
\hline $\begin{array}{c}\text { Stage of Risk } \\
\text { Assessment }\end{array}$ & Factor & Summary \\
\hline $\begin{array}{c}\text { Hazard } \\
\text { Identification }\end{array}$ & $\begin{array}{l}\text { Origin: } \\
\text { natural/technological }\end{array}$ & $\begin{array}{l}\text { - Technological (man-made) hazards include use of hormones, pesticides, antibiotics and genetic modification. } \\
\text { - Hatural hazards include those related to food hygiene and diet. } \\
\text { technor risk perceptions, increased concern levels and lower acceptance ratings are seen for man-made, } \\
\text { tigards. }\end{array}$ \\
\hline $\begin{array}{c}\text { Hazard } \\
\text { Characterisation }\end{array}$ & Dread & $\begin{array}{l}\text { - Assessment of dread relates to: likelihood of harm, seriousness of harm, seriousness for future } \\
\text { generations/vulnerable groups, potential for disastrous consequences, delayed effects and severity. } \\
\text { - Hazards scoring highly on dread include microbiological contamination (e.g., salmonella, botulism), produce } \\
\text { containing pesticide or hormone residue, GM/irradiation technology and BSE. } \\
\text { - Key component of risk judgements. Increased risk perceptions, levels of concern and worry are seen for } \\
\text { hazards scoring highly on dread. }\end{array}$ \\
\hline & Unknown & $\begin{array}{l}\text { - Unknown factor relates to level of scientific knowledge, accuracy of assessments, the extent to which people } \\
\text { know if the food contains the risk, and level of control over the risk. } \\
\text { - Hazards scoring highly on unknown dimension include GM technology and food irradiation. Lower scores are } \\
\text { given to dietary, nutritional and microbiological hazards. } \\
\text { - Key component of food risk judgements. Increased risk perceptions and levels of concern are seen for } \\
\text { hazards perceived as unknown. }\end{array}$ \\
\hline & Benefits & $\begin{array}{l}\text { - Typically, risk and benefit perceptions are negatively correlated - hazards that are high in benefit are } \\
\text { perceived as low in risk and vice versa. }\end{array}$ \\
\hline
\end{tabular}




\section{Exposure}

Assessment

Population identity

Proportion of

population exposed

Time frame

Involuntary nature of exposure

Risk

\section{Characterisation}

Qualitative
- Hazards which specifically affect children, threaten future generations or affect vulnerable groups (e.g., the elderly) are associated with increased levels of worry and concern.

- Examples include GM technology, food irradiation and pesticides.

- 'Number of people exposed' contributes to perceived dread or severity, and thus risk perceptions.

- Hazards perceived to affect large amounts of people include environmental contaminants, BSE, pesticide residue, salmonella, listeria and botulism.

- Format used to express proportion of population exposed can influence interpretations - higher risk perceptions when a frequency format is used (e.g., affects 10 out of 100) versus a percentage format (e.g., $10 \%)$.

- Problematic that typically more is known about the acute (rather than chronic) effects of a hazard - feeds into 'unknown' factor, which explains increased concern for long-term effects of pesticide use, GM technology, and chemical contaminants.

- Events with immediate consequences are perceived as more serious than those that are delayed.

- Units used to express time influences risk perception - increased likelihood perceptions when expressed in terms of days versus years.

- Involuntary risks are those which one is exposed to without prior consent or knowledge, and, as such, are uncontrollable. Associated with dread factor.

- Involuntary food risks include eating GM food, or food containing food colouring.

- Increased risk perceptions and levels of concern, and lower levels of acceptability are seen for risks perceived as involuntary.

Evaluative labels (e.g., 'low', 'medium' or 'high') are associated with highly variable interpretations, which can influence risk perceptions, levels of worry and behavioural intentions.

- Verbal probability expressions (e.g., 'likely', 'unlikely') are also associated with highly variable interpretations, which can influence risk perceptions, lead to overestimations of risk, and risk management decisions.

- Point estimates can relate to outcomes (e.g., an ADI of $1 \mathrm{mg}$ ) or probability (e.g., 1\% likelihood).

- They are overly simplistic, and portray a false sense of precision, which people may try to correct for. 
- Range estimates can also relate to outcomes (e.g., an ADI of $0.5-1 \mathrm{mg}$ ) or probability (e.g., $10-30 \%$ likelihood).

- Interpretation of outcome ranges (i.e., reflecting uniform/normal distribution) can vary, though this is

lessened with provision of a best estimate.

- Caution should be used if presenting ranges using expressions such as 'more than/above $x^{\prime}$ as they convey additional pragmatic information, directing attention to how the number should be interpreted. 